\title{
Linguistics Textbooks in Greek: Publication Practices in the Last Three Decades
}

\author{
George J. Xydopoulos ${ }^{1}$, Anastasios Tsangalidis ${ }^{2}$ and Athena Prountzou ${ }^{1}$ \\ ${ }^{1}$ University of Patras, ${ }^{2}$ Aristotle University of Thessaloniki \\ gjxydo@upatras.gr, atsangal@enl.auth.gr, aprou@upatras.gr
}

\begin{abstract}
In this paper we examine the development of linguistics textbooks published in Greece over the last three decades. We conducted a survey of all textbooks published from 1980 to date and processed all publishing characteristics in quantitative terms as well as a questionnaire-based survey of the opinion of faculty teaching linguistics in Greek universities. Based on the qualitative analysis of these data we found that textbooks have developed substantially over the last 30 years in both their readability and usability attainment and so they appear to serve their educational functions with success. However, there is an increasing need for new textbooks, preferably, originally written in Greek, or sufficiently adapted to the Greek language, in many fields of both microlinguistics and macrolinguistics and, in particular, in generative syntax, formal semantics and phonology and more titles in morphology and lexicography. Furthermore, there is also urgent need for (more or up-to-date) textbooks in interdisciplinary fields including cognitive linguistics, psycho / neurolinguistics (including L1 / L2 acquisition) and dialectology with systematic reference to Greek as well as critical approaches to linguistics (e.g. critical discourse analysis).
\end{abstract}

\section{Introduction}

In this paper we attempt to describe the publishing activity of linguistics textbooks in Greece, over the last thirty years, on the basis of quantitative and qualitative data. Our work falls within the field of educational linguistics with emphasis on the teaching of linguistics in higher education (cf. Lier 1994: 203ff). Our purpose is multifaceted. First, we wish to initiate a discussion regarding the current situation of linguistics studies in Greece, focusing on textbooks. In the

\section{(cc) BY-NC-ND}


meantime, we would like to stress the importance of publishing textbooks for the promotion of linguistics studies in Greece. Furthermore, we aim at providing an accurate record of linguistics book publishing in Greece since the 1980's and attempt to determine needs for publishing more textbooks in Greek in various fields of linguistics.

The paper is organized as follows. In section 2, we discuss definitional issues regarding the genre of "textbooks", on the basis of the relevant literature in educational linguistics. In section 3, we examine the appropriate design criteria for the creation of textbooks as opposed to books of other genres. In section 4, we investigate the history of linguistics books publishing in Greece for the last thirty years in both quantitative and qualitative terms. In section 5, we conduct a pilot survey of the opinion of teaching staff regarding fundamental aspects of the function of linguistics textbooks in the educational process. Finally, in section 6, we identify positive features, highlight problem areas and make suggestions for the future of publishing Greek linguistics books.

\section{What are Textbooks?}

According to Stray (1991) and Johnsen (2001), textbooks can be defined as books specially written and published for educational purposes and, in some cases, also usable in the classroom. Therefore, textbooks may also be defined as a subcategory of teaching media. Other types of books can also be used as "textbooks" when introduced in the teaching process, though they may not be used as textbook-substitutes. Obviously, despite some functional similarities, textbooks are clearly distinguished from schoolbooks.

\subsection{A little History}

The history of textbooks begins around the 1830s. More than a century later, in the 1950's, textbooks contain no illustrations, their text is fairly dense, the page layout is not attractive and the language used therein is difficult with vast use of passive voice, nominalized structures and complicated sentences. Forty years later, in the 1990's, textbooks become more user-friendly as they appear with more illustrations as well as concise text and short active sentences. In the same decade, textbooks become student-centered by actively involving the student in the learning process. This is realized by asking students questions about the material taught, by offering self-practice opportunities through exercises and activities, etc. (see e.g. Sutton 1989, Davies 1999, Johnsen 2001, Wellington \& Osborne 2001). 


\subsection{Some Functions of Textbooks}

In order to understand the nature of the genre and their fundamental difference from other genres of scientific books it is important to consider the chief functions of textbooks. According to Issitt (2004: 683-4), textbooks are a quite 'fuzzy' category. They are not a mere exposition of ideas but "trace, explain and illuminate ideas and developments". Indeed textbooks reflect a creative input to scientific research and formalize knowledge so as to be consumed by students. Furthermore, they are referred to for better understanding, are used for revising taught material for exam preparation and, at the same time, are revisited for any need for learning practice (e.g. exercises, queries, case-studies etc.).

Therefore, if we adopt Issitt's (2004: 685) definition we can view "textbooks" as "a focused educational programme in text allied to a scheme of work". This is a representative and unbiased definition that incorporates both the form and function of textbooks and highlights their role as a teaching medium.

\subsection{Usability of Textbooks in the Classroom}

Following Wellington \& Osborne (2001: 103ff), we attribute great importance to the educational function of textbooks. Koch (2011: 66-67, 69-71), Partee (2011: 41-48) and Potts (2011: 59), among others, believe that textbooks are used in the classroom for various reasons, such as: (a) to support practical work and suggest class work and homework tasks through exercises and activities; (b) to supplement the class, by providing more detailed information about the subject; (c) to illustrate various concepts, through diagrams, tables, illustrations; (d) to introduce students to the topics of the course, by hierarchically and logically organizing chapters and sections; (e) to provide a revision or reference guide, e.g. for exam preparation; (f) to serve as a manual for self-study, through its defined structure, accessibility, content and pedagogical style; and (g) to support the teacher in the organization and smooth operation of the whole educational process, depending on its relevance to the content of the course.

\subsection{Readability: the Decisive Criterion for Textbooks}

Following Davies (1999: 338ff) and Wellington \& Osborne (2001: 109ff), among others, we consider readability as the most important qualitative criterion for textbooks. A highly readable textbook is one that is appealing to the reader, thanks to its good appearance, and is well-structured and laid out, as it is organized in chapters and sections with proper headings and well paragraphed. Expectedly, the text in a highly readable textbook is clear and fluent, supported by illustrations and diagrams, while all keywords are properly flagged in the text. 


\section{The Survey}

Our investigation of Greek linguistics books consisted of two stages. In the first stage, we conducted a survey of linguistics books published in Greek by collecting, classifying and measuring the relevant publishing data. In the second stage, we made a preliminary survey of the opinion of linguistics teachers with the use of a short questionnaire that focused on the degree of satisfaction from textbook use. Our informants were faculty members employed in linguisticsrelated departments of Greek universities, namely "Philology", "Foreign Language and Literature", "Primary" and "Pre-school Education", and other humanities departments that include linguistics in their undergraduate curriculum.

\subsection{A Survey of Linguistics Textbooks Published in Greek}

Our survey of linguistics textbooks consisted of five major steps. First, we located a total of 426 titles published from 1980 to date in Greece, by searching in library databases and publishers' catalogues. Second, we classified our findings into five genres: (a) grammars (linguistic descriptions of Greek); (b) treatises (single-volume investigations of specific subjects); (c) reference (terminology dictionaries and glossaries); (d) monographs (articlelike investigations focused on a narrowly specified subject); and (e) textbooks (introductory books to specific fields of linguistics, recommended to students as indispensable course material; defined earlier in section 2). Third, having excluded all books of other genres, we classified textbooks in 18 major fields of linguistics ${ }^{1}$. Fourth, we formally examined textbooks on the basis of their publishing characteristics, that is, the publisher, the place and year of publication and the language of the original text. Fifth, we assessed all our findings in quantitative terms and we drew qualitative conclusions. In the subsections that follow we discuss each of these steps in more detail.

\subsection{A Preliminary Survey of Linguistics Teachers' Opinion}

We thought that an important ingredient in our research was to survey teachers' opinion about the use of textbooks. This allowed us to see

1 Namely: General Linguistics, Syntax/Semantics, Pragmatics/Discourse Analysis, Phonetics \& Phonology, Morphology, Historical Linguistics, Lexicology/Lexicography, Sociolinguistics, MG Description, Cognitive Linguistics, Psycho/Neurolinguistics, L1/L2 Acquisition, Educational Linguistics, History of Linguistics, Dialectology, History of Greek, Philosophy and Stylistics. 
aspects of the constitution of textbooks that cannot be straightforwardly quantified.

To this end, we designed a questionnaire-based survey by applying special attention to issues of professional and academic ethics. Of course, this added specific restrictions and limitations to the quality and force of questions and the depth of expected responses.

In particular, we created a one-page anonymous questionnaire that comprised one fill-in question asking the informant to fill in the courses $\mathrm{s} / \mathrm{he}$ taught as well as six attitude scale questions eliciting subjective response; also allowing for short comments (Appendix I). These questions targeted the teacher's opinion about the quality of the textbook and its reliability to support the educational process. The first question was about how much of taught material for each course is covered by the book. The second question asked the teacher to assess the usefulness of the textbook for teaching and learning. The third question asked the informant to judge how relevant the textbook was for Greek, in terms of the phenomena covered, the data presented and discussed, the applicability of the concepts discussed, etc. The fourth question in the survey was for teachers to judge how "pedagogical" they found each textbook thanks to its organization, content and simplicity of language. The fifth question was to examine the way technical terms were managed in the book pertaining to accuracy, objectivity and documentation in the treatment of terminology in Greek. Finally, the sixth question looks to measure teachers' general impression of the textbooks.

We determined 34 departments in Greek universities as relevant to our research as their linguistics courses formed part of their undergraduate curriculum. These were the departments of "(Greek) Philology" in the universities of Athens, Thessaloniki, Patras, Crete (Rethimno), Ioannina, Thrace (Komotini) and Peloponnese (Kalamata); the departments of "English", of "French", of "German" and of "Italian \& Spanish" "language and literature" in the universities of Athens and Thessaloniki; the departments of "Pre-school" and of "Primary Education" in the universities of Athens, Thessaloniki, Patras, Western Macedonia (Florina), Crete (Rethimno), Aegean (Mytilini), Thessaly (Volos) and Thrace (Alexandroupolis); the department of "Translation Studies" in the university of the Ionian (Corfu); and three other humanities departments in the universities of the Aegean (Rhodes), Thessaly (Volos), Thrace (Alexandroupolis) that offer a diet of linguistics courses. We located and contacted, by e-mail, all teachers of linguistics holding permanent positions in these departments and asked them to fill in and return the questionnaire. 


\section{Quantitative Analysis of Greek Linguistics Textbooks}

Following the collection of necessary data we conducted a quantitative analysis of textbook features. Our analysis included the classification of linguistics books in different genres, the publishing activity of such textbooks, the original language of the textbooks, the academic profile of authors and translators, the linguistics fields concerned and the response of teaching staff to questionnaire and textbook evaluation.

\subsection{Linguistics Books Genres}

The bar diagram given in Figure 1 presents the distribution of textbooks across five genres. We observe that the majority of linguistics textbooks published in Greek (i.e. 65.02\%) belong to the genre of "treatises", while only $23.71 \%$ of them fall within the category of "textbooks". Grammars, monographs and reference books form just $11.27 \%$ of the total of Greek linguistics titles published.

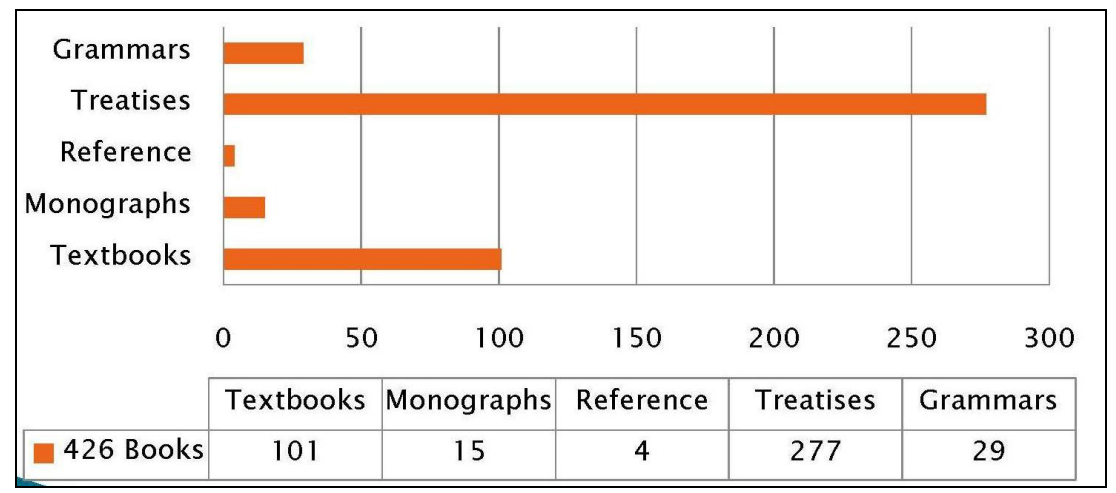

Figure 1. Textbooks per genre

\subsection{Publishing Activity from 1980 to Date}

The majority of textbooks (57\%) were published during the period from 2000 to 2009 . Only $12 \%$ of textbooks were published during the 1980 's, a figure that was almost doubled in the 1990's, showing an ascending tendency, justified by the increasing popularity of linguistics in those years. Publishing of 
Greek linguistics textbooks doubled in each following decade. Current decade (2010-to date) indicates a tendency of intense publishing, comparable to the previous one, as 5 new textbooks were published in a period of just one and a half year.

\subsection{Place of Publication}

As expected, the publishing activity of linguistics textbooks is represented by publishers based either in Athens or Thessaloniki. The majority of linguistics books we considered, $72.28 \%$, were published in Athens, and the rest in Thessaloniki (27.72\%) In Athens, 23 different publishing houses were more or less active in publishing linguistics textbooks. A small portion of publishing in Athens during the 80's was private as authors of linguistics textbooks published their books on their own. In Thessaloniki, 6 different publishing houses have published linguistics textbooks since the 80 's, including intensive publishing activity by two non-profit research institutes.

\subsection{Textbook Language}

A comparative distribution of translated and non-translated linguistics textbooks across the four periods studied (Figure 2 ) indicated the preference in writing original titles directly in Greek rather than translating foreign textbooks; this is apparent, especially from 2000 onwards. As we will see in the discussion of questionnaires results (Section 4.9), this fact is generally welcomed by the majority of linguistics teachers.

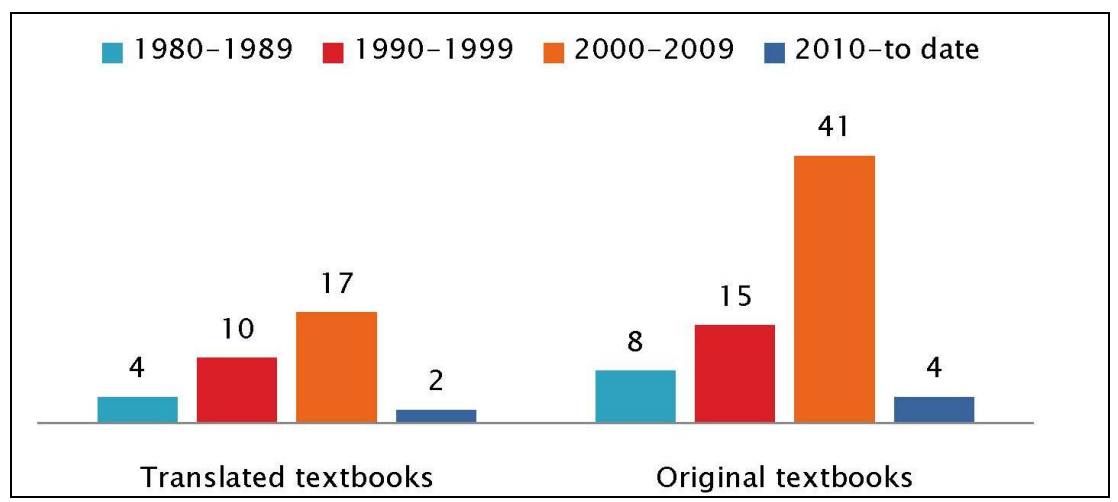

Figure 2. Textbook language 


\subsection{Source-language of Translated Textbooks}

The majority of translated textbooks examined (67\%) appeared to have originated from works originally written in English. French is the second sourcelanguage (24\% of textbooks), as the majority of translated textbooks of the 1980 's originated from French books. Greek textbooks based on German and Italian original books constitute just $9 \%$ of the total.

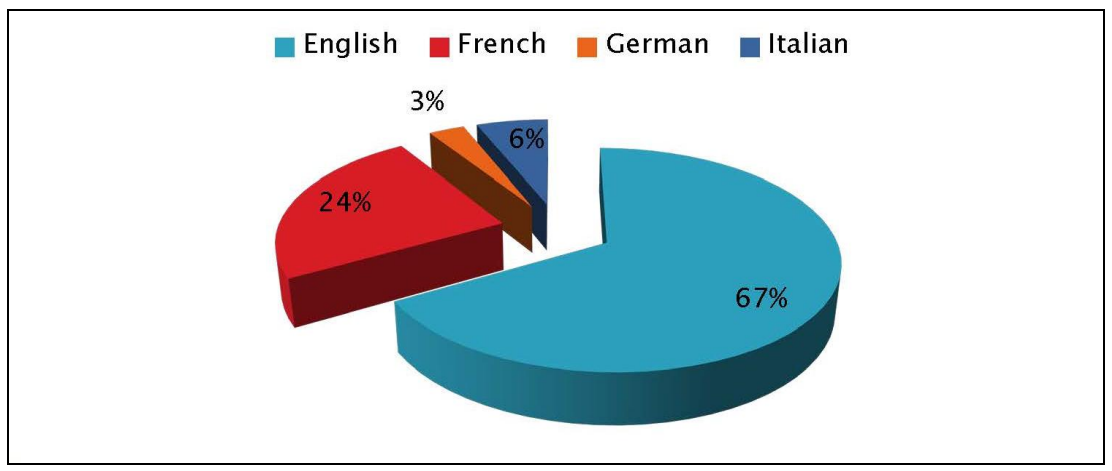

Figure 3. Source-language for translated textbooks

\subsection{Translators' Profile}

The translation of foreign textbooks into Greek, in its majority (85\%), is done by experts in the field. In recent years, roughly since 2000 , translators are usually junior members of linguistics faculty or recent PhD in linguistics holders.

\subsection{Textbooks Publishing in Each Field}

The distribution of Greek linguistics textbooks in our survey falls across 18 different fields of the discipline (see the line diagram in Figure 4). We found that that there has been a general tendency in publishing textbooks in the areas of General Linguistics (mostly introductions to the discipline), of Educational Linguistics (mostly regarding L1 teaching) and of the (quite popular) history of Greek (Ancient, Modern or a combination of the two). A noticeable publishing activity is also observed in traditional fields of microlinguistics, such as Syntax and Semantics although these are not necessarily formalistic. A tendency that started appearing during the last decade was to publish textbooks in the areas of sociolinguistics, pragmatics and discourse analysis, showing a turn to more interdisciplinary and applied linguistics subjects. 


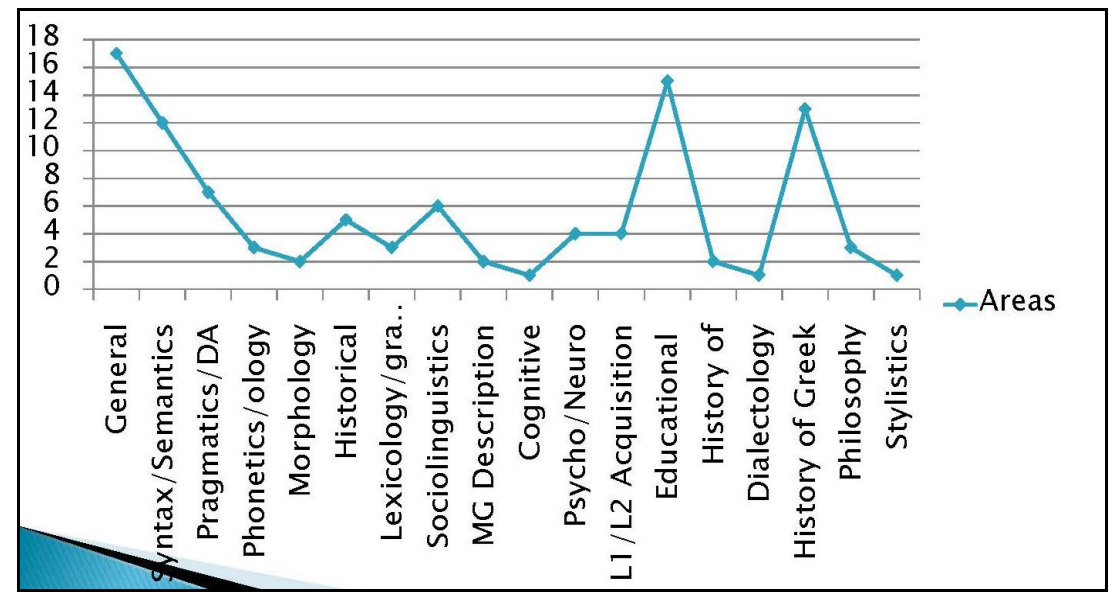

Figure 4. Titles per linguistics field

\subsection{Teachers' Response to Questionnaire}

We noticed a low level of response to the questionnaire among colleagues (a total of 31 informants), especially from foreign language departments. This was expected as the majority of courses they teach are based on foreign textbooks, and only few of them use Greek textbooks as supplementary resources. The majority of responses that were qualitatively-relevant to our research came from faculty in the "Greek philology" departments (see Figure 5).

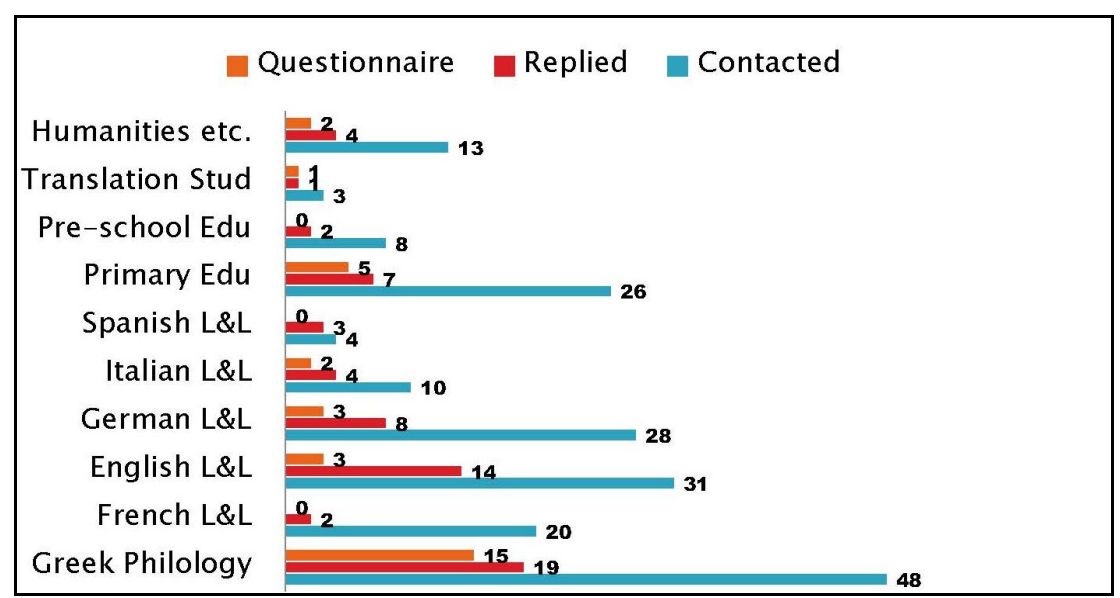

Figure 5. Staff response to the questionnaire 


\subsection{Evaluation Results}

Our survey revealed that, in general, members of staff are happy with Greek linguistics textbooks in all aspects, giving a mean grade of 3,48 out of 5 (see the combined column diagram in Figure 6). Staff found that textbooks have a good coverage of the material taught and are quite relevant to Greek language. The treatment of terminology and the pedagogic profile of the textbooks examined seem to be slightly problematic aspects that need more attention by authors and publishers.

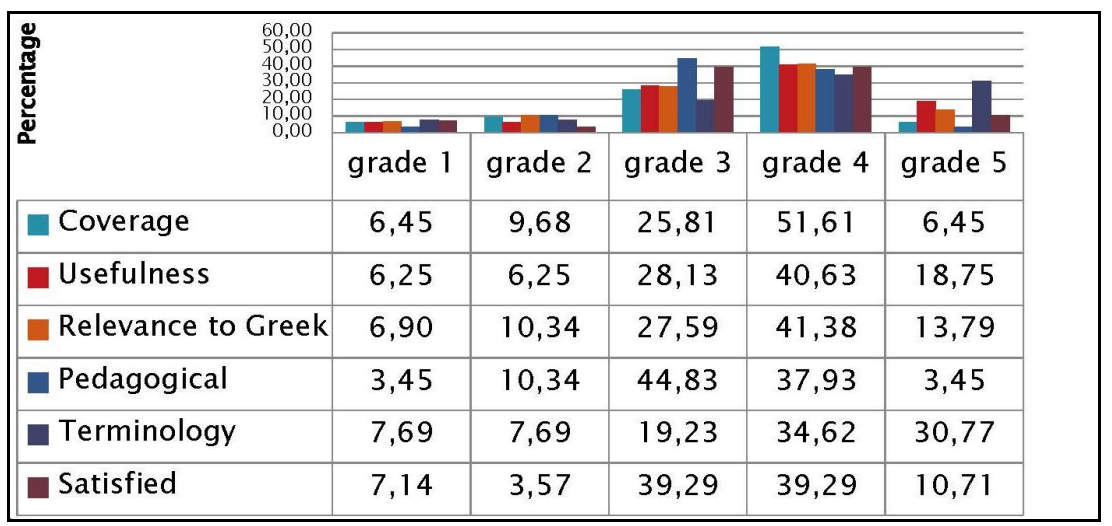

Figure 6. The opinion of teaching staff

These quantitative findings are further verified by informants' individual comments. So, some teachers do not like using textbooks and do not recommend them to their students at all. They think textbooks just encourage students to reproduce the text without developing their knowledge and skills. A few teachers also find that some textbooks are traditional and not up-to-date with current trends in linguistics. Teachers also report that in some cases textbooks do not apply the analysis to Greek data and the discussion in text is not relevant to Greek either. Finally, problems regarding the translation of foreign technical terms are also reported stressing the fact that in many cases there is no unanimity about the Greek equivalents in linguistics terminology (cf. Xydopoulos 2002 and Moschonas 2003).

\section{An Evaluation of Greek Linguistics Textbooks}

Let us now decide about the suitable criteria for measuring Greek textbooks in terms of whether they fulfill the definitional conditions we discussed earlier in section 2. Following the relevant literature, we understand that "textbooks" 
are a special genre of scientific book with a clear educational purpose. In other words, textbooks are real educational media, so, they should be communicative, instructing and informative as they address a rather "novice" readership in a specialised field. Therefore, we assume that proper textbooks should display a high degree of readability and usability in order to be of good service to both the teacher and the learner.

\subsection{Readability Criteria}

In this section we propose a mapping of readability features to an applicable set of measurable criteria for readability (see Appendix II) following the ideas of Davies (1999) and Wellington \& Osborne (2001: 103-116). Each feature corresponds to a set of measurable criteria for readability. Of course, a measurable criterion can correspond to multiple readability features.

The first readability feature concerns the structure of the textbook which needs to be clear and hierarchical. This feature is obtained in a textbook if chapters and sections are hierarchically structured and properly headed. Clarity can also be achieved if there is a summary after each chapter, to facilitate readers remembering the main claims and ideas discussed. The existence of a proper index and a references section, among other things, makes a textbook more readable as it offers users the possibility of finding exactly what they are looking for and gives them the opportunity for further reading in the field.

If a textbook is appealing to the reader then, we believe, it becomes more readable. There are several things that can make a book appealing to its readership, both intrinsic and extrinsic. Clarity of structure, as defined above, along with the necessary illustrations, in the form of pictures, diagrams, figures, tables etc. are features that can improve textbooks' readability and teaching supportive function. In addition, if a textbook contains flagged terms in its body text, a summary and practice exercises after each chapter then it becomes substantially friendlier and more useful to its readers.

A high degree of readability in a textbook is also obtained if reader's attention is systematically drawn to key terms discussed in text. To achieve this, a textbook needs to have one or more terms indices, a mono/bilingual glossary with brief definitions as well as flagged terms in body text linked to the indices and glossary. This allows readers to find all information they need quickly and accurately.

A definitional characteristic of textbooks, as opposed to other genres of scientific text, is the fact that they link theory to practice. Readers need sufficient exposure to practice exercises and other (simulation) activities so as to be facilitated in their learning of the study material. So, if a linguistics textbook discusses various concepts with application to the data of a specific language 
(e.g. Greek in our case) and contains the necessary sets of practice exercises/ activities and illustrations (pictures, tables, diagrams) it arguably has a high degree of readability.

Finally, we believe that a textbook is more readable if it is sufficiently informative for the purposes of individual readers whose needs and assumptions may not be identical. Chapters and sections hierarchically structured and properly headed, a summary after each chapter and flagged terms in body text are characteristics that are also important for a textbook to achieve a sufficient degree of informativity as defined (subjectively) by the needs of individual readers. Apart from these, informativity is also achieved if a textbook includes all sections that are peripheral to the text but offer the user comprehensive information about the book. These peripheral sections include a mono/bilingual glossary, foot/endnotes, the author's CV and back cover details. Finally, for a textbook to be informative its title needs to be sufficiently general, that is to instantly inform the readership about its content.

\subsection{Usability Criteria}

Along with readability, usability is equally important for a textbook to achieve its educational goals. As we did earlier with readability, in this section we propose a translation of usability features to an applicable set of measurable criteria for usability (see Appendix III). Here too we can see that each feature corresponds to a set of measurable criteria for usability and, of course, a measurable criterion can correspond to multiple usability features (see e.g. Davies 1999 and Issitt 2004: 684-695).

The first criterion for "usability" is for the textbook to support practical work / class work / homework. Obviously, this can only be achieved if the book includes sets of practice exercises and activities that can be used for teaching and learning. Usability is also increased if a textbook is designed in such a way that the theoretical discussion is properly applied to linguistic data that are familiar to the reader. This criterion is also fulfilled if the textbook includes an index of terms, a mono/bilingual glossary and summaries after each chapter as they allow the user to easily find all information without the teacher's intervention.

The second criterion for usability is for the textbook to supplement the teaching process by offering the user all options for self-study and selfevaluation. Obviously, if a textbook has practice exercises/activities for the reader to apply theoretical knowledge and self-evaluate learning then it becomes highly usable. Similarly, proper referencing offers readers the opportunity to expand their studying on the subject. Illustrations of concepts and data analysis and a glossary of terms further supports the reader in his/ her learning effort and enriches his/her teaching experience. Finally, a good and 
hierarchical organization of chapters and sections offers readers the opportunity to study in an organized and systematic manner.

The third criterion for usability is the effectiveness of the textbook in successfully introducing novice students to the topics. We find that to do so a textbook needs to be hierarchically organized in chapters and sections with proper headings. Furthermore, it needs to include a summary after each chapter and a glossary, for revision purposes, as well as proper illustrations and application to language-specific data to offer students sufficient and clear information in their (self-) study experience.

A high degree of usability of a textbook is also achieved if (new) concepts are illustrated and explained in detail. To this end, pictures/tables/diagrams are necessary ingredients in the structure of each chapter, along with summaries, a glossary and sufficient and familiar language data for better understanding the mechanisms and phenomena involved.

A textbook is highly usable if it can function as a revision or reference guide and as a self-study material. Therefore, such a textbook is expected to combine different study means, including: a hierarchical structure with an index of terms, a glossary, practice exercises and activities, revision summaries after each chapter and proper flagging of technical terms in the text.

Finally, a textbook needs to be usable in teaching too. So, teachers and students need to be able to use the textbook during the teaching process. The organization of chapters and sections can guide or follow the teaching programme, so hierarchy and organization are necessary. Practice exercises and activities can serve either as homework assignments, project subjects or examination questions (if altered accordingly). Obviously, illustrations in the textbook can be referred to or discussed during teaching to facilitate explanation and understanding.

\subsection{Readability and Usability of Greek Textbooks: The Results}

In this section we consider the comparative results from the application of readability and usability criteria, we discussed in the previous sections, to Greek textbooks published in the last three decades. Results generally indicate that Greek textbooks satisfy almost all criteria of readability and usability, gradually, from 1980 to date.

Figure 7 offers a comprehensive view of the readability and usability features we determined and measured in our sample of Greek textbooks published from 1980 to date. In particular, only 42\% of textbooks in the 1980's had a hierarchical organization of their content. This partially increased in the 1990's and, since 2000, all Greek textbooks ate hierarchically structured. 


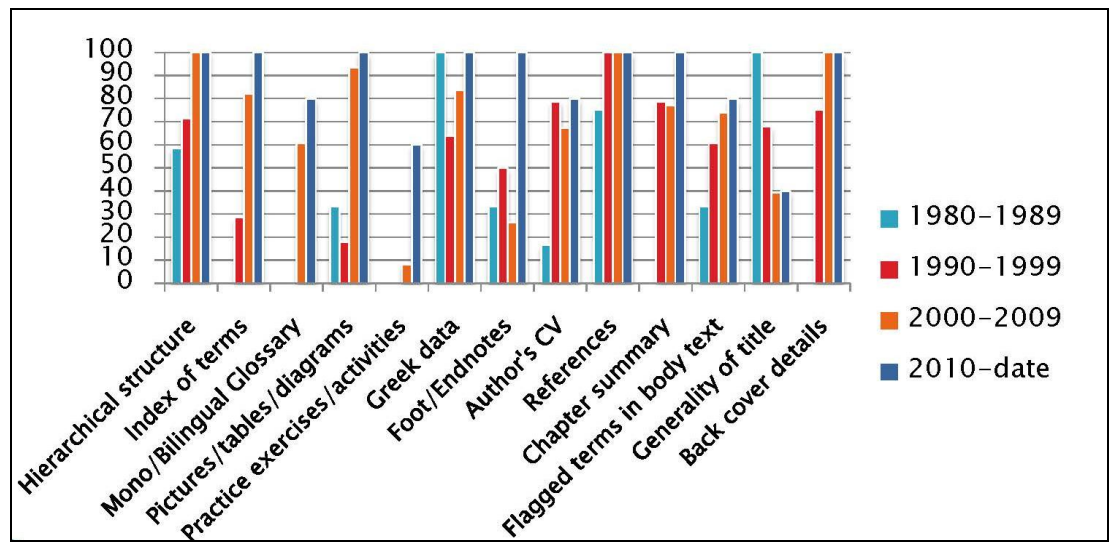

Figure 7. Readability and usability features in the history of Greek texbooks

An index of terms was absent from Greek textbooks of the 1980's. This feature has been added to $90 \%$ of the textbooks published since 2000 . The same holds for glossaries which, although completely absent in the 1980's, appear in $70 \%$ of textbooks since 2000 . Similarly, pictures/tables/diagrams appeared in just 30\% of textbooks in the 1980's and the 1990's and were added to almost $95 \%$ of textbooks from 2000 onwards. Practice exercises/ activities were also absolutely absent in all textbooks of the 1980's and 1990's and, since 2000, they started appearing in a few titles. Since last year, practice exercises/activities were included in $60 \%$ of textbooks published.

Greek data appeared in $80 \%$ of textbooks published between 1980 and 1999 and reached almost 95\% during the last decade. Foot/Endnotes were used (mostly for referencing) in approximately 35\% of textbooks from 1980 to 2009. In 2011, the use of foot/endnotes for commentary purposes has increased to $100 \%$. Authors' CVs were not included in many textbooks of the 1980's but were added to almost $80 \%$ of textbooks published to date. References appear in almost all textbooks since 1980 with a few exceptions where there was no bibliography at all or only a selection of indicative references was available. Chapter summaries were not available in textbooks published the 1980's but were added to almost $75 \%$ of textbooks published after 1990. Similarly, flagging of key terms in body text is a feature that appeared in only $35 \%$ of textbooks in the 1980's but gradually increased to $80 \%$ of textbooks published in the last two decades. The titles of textbooks were general in the 1980's and since then they have become more specific with or without the use of a subtitle. Finally, with the exception of textbooks published in the 1980's, almost 85\% of titles published since 1989 display book details in the back cover. 


\subsection{A Note on Non-measurable Qualitative Criteria}

In our research we did not evaluate quality of text as it is a qualitative criterion for readability that cannot be measured. A readable textbook of high quality is one that is clear, direct and simple in structure and vocabulary. Its text is brief and concise, it is balanced in information quantity and contains short, properly interconnected and one-idea sentences. Finally, such a textbook motivates and directly addresses the reader (see e.g. Wellington \& Osborne 2001).

The question about the quality of text also applies to translated textbooks where special attention needs to be paid to the adaptation of linguistics metalanguage from source to target language (including terminology and standard expressions) and to the translation of examples, illustrations and exercises (see e.g. Xydopoulos 2002)

Judging from the comments made by the teachers in the evaluation questionnaire we assume that modern Greek textbooks fulfill the criterion of text quality to a satisfactory level. In impressionistic terms, we can say that the majority of textbooks that appeared in the 1980's and 1990's are considered less readable (and usable) as they reflect textual and stylistic trends of that period when scientific books were written in a more complicated language and more formal style (i.e. extensive use of impersonal structures, passive voice, nominalisations etc.). The majority of textbooks published since 2000 are taken to be more readable as they generally use a more relaxed style and engage in a pedagogical "conversation" with the reader, imitating the usual practices found in foreign (mostly English) textbooks.

\section{Dominant Linguistic Paradigms and Publishing Tendencies}

Let us now have a quick look at the dominant linguistic paradigms (cf. Robins 1997) and publishing tendencies for Greek textbooks in the past thirty years.

Textbooks of the 1980's placed emphasis on theoretical linguistics and levels of analysis and mainly focused on structuralist linguistics (European and/or American schools). By the end of the decade, they attempted an introduction to generative linguistics, though without clearly opposing the two schools of thought. Other textbooks, in the same period, focused on the history of Greek (from AG to MG) applying rather philological than purely linguistic approaches. Textbooks of the 1980's showed an important influence mostly from linguistics in France than in the UK or the US.

Textbooks of the 1990's show a turn from structuralist to generative linguistics, while still maintaining traditional historical approaches to Greek. However, in this 
decade there were textbooks dealing with various fields of applied linguistics e.g. sociolinguistics, text linguistics, psycholinguistics, pragmatics, philosophy of language, discourse analysis, L1 teaching etc. Many textbooks of this decade were translations from English renowned textbooks with minimal or substantial adaptation to the particularities of the Greek language.

Textbooks of the first decade of this millennium showed a tendency to deal with as many linguistics fields as possible. An important number of textbooks were adaptations of new (mostly) English textbooks in various fields of general and applied linguistics. Major publishers invested in linguistics textbooks during the first decade of the millennium. A strong tendency was also observed in publishing (either original or translated) textbooks in the new field of educational linguistics with emphasis on language teaching, literacy and multilingual education. During this decade, textbooks were either translated or written by junior linguists, while, some older but renowned titles from the 1980's and 1990's also appeared in newer editions with major improvements towards higher degree of readability and usability.

At the beginning of the second decade of this millennium we observe similar tendencies to those of the previous decade. However, there is a new tendency in publishing multiple textbooks per field thus giving the opportunity to students, teachers and other users to choose from a variety of titles or to be able to consult multiple sources.

\section{Conclusions and Suggestions}

In this work we studied the development of textbooks publishing in Greece during the last three decades. So, in section 2, we discussed definitional issues regarding the genre of "textbooks", following the relevant literature. We found that textbooks are not an ordinary type of book as their chief function is to serve as a multifaceted teaching and learning medium. Therefore we understood that they should not be treated as an inferior genre or used as a derogatory term. As we saw in section 5, we conducted a survey of all textbooks published from 1980 to date and processed all publishing characteristics in quantitative terms. We also conducted a questionnaire-based survey of the opinion of colleagues teaching linguistics in Greek universities. We were able to collect interesting data from both surveys. Based on the qualitative analysis of these data in section 5.4, we found that textbooks have developed a lot over the last 30 years in both their readability and usability attainment and so they appear to serve their educational functions with success. In other words, there are indeed good Greek textbooks in linguistics (both original and translated) as confirmed by the vast majority of teachers. However, as we showed in section 6, there is an increasing need for new textbooks, preferably, originally written in Greek, or sufficiently adapted to 
the Greek language, in many fields of both microlinguistics and macrolinguistics. More particularly, we believe that there is an urgent need for more up-todate textbooks in generative syntax, formal semantics and phonology and more titles in morphology and lexicography. Furthermore, there is also urgent need for (more or up-to-date) textbooks in interdisciplinary fields including cognitive linguistics, psycho/neurolinguistics (including L1/L2 acquisition) and dialectology with systematic reference to Greek as well as critical approaches to linguistics (e.g. critical discourse analysis). Certainly, our research has several drawbacks as it did not record students' feelings towards linguistics textbooks and did not investigate content and textual issues of textbooks in some detail. We leave these issues for further research. 


\section{References}

Davies, F.I. 1999. Textbooks. In B. Spolsky (ed.) Concise encyclopedia of educational linguistics. Amsterdam: Elsevier, 337-343.

Foster-Cohen, S. 2011. Teaching language acquisition. In K. Kuiper (ed.). Teaching Linguistics. London: Equinox, 137-144.

Issitt, ]. 2004. Reflections on the study of textbooks. History of Education 33.6, 683-696.

Johnsen, E. 1993/2001. Textbooks in the Kaleidoscope: A Critical Survey of Literature and Research on Educational Texts (Translated by L. Sivesind). Oslo: Scandinavian University Press.

Koch, H. 2011. Teaching historical linguistics: A personal memoir. In K. Kuiper (ed.). Teaching Linguistics. London: Equinox, 66-86.

Lier, L. van 1994. Educational linguistics: Field and project. In J. Alatis (ed.) Educational linguistics, crosscultural communication, and global interdependence. Washington, DC: Georgetown University Press, 197-209.

Moschonas, S. 2003. Prin apo ti didaskalia tis elinikis os ksenis glosas [Before teaching Greek as a foreign language]. In D. Theofanopoulou-Kontou, C. Laskaratou, M. Sifianou, M. Georgiafentis and V. Spyropoulos (eds) Sinxrones taseis stin eliniki glosologia [Current trends in Greek linguistics]. Athens: Patakis, 87-107.

Partee, B.H. 2011. On teaching formal semantics. In K. Kuiper (ed.). Teaching Linguistics. London: Equinox, 40-50.

Potts, C. 2011. Teaching pragmatics. In K. Kuiper (ed.). Teaching Linguistics. London: Equinox, 51-65. 
Robins, R.H. 1997. A short history of linguistics ( $4^{\text {th }}$ edition). London: Longman.

Stray, C. 1991. Paradigms Lost: Towards a Historical Sociology of the Textbook. Paper presented in the PEXU Conference, Härnösand, Sweden.

Sutton, C. 1989. Writing and reading in science: the hidden messages. In R. Millar Doing Science: images of science in science education. Lewes: The Falmer Press, 137-159.

Wellington, J. and J. Osborne. 2001. Language and literacy in science education. Buckingham: Open University Press.

Xydopoulos, G.J. 2002. Metafrazontas ena epistimoniko singrama: diskolies ke pithanes lisis [Translating a scientific textbook: difficulties and possible solutions]. In Proceedings of the International Conference "Translating in the 21st Century: Trends and Perspectives", Aristotle University of Thessaloniki, 740-751. 


\title{
Appendix I
}

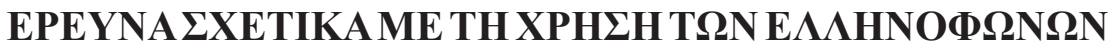

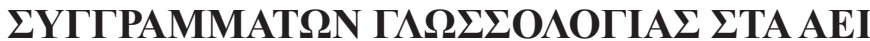

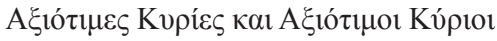

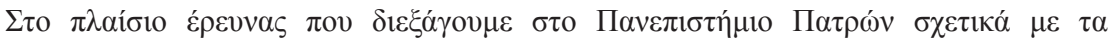

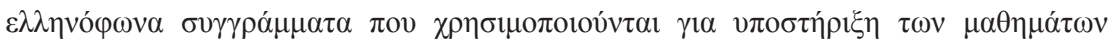

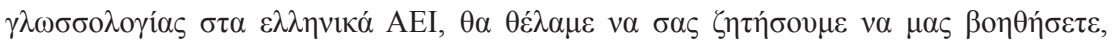

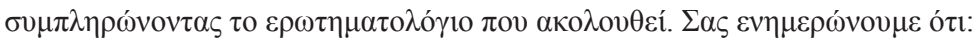

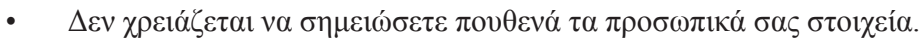

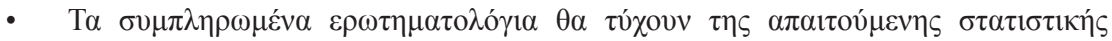

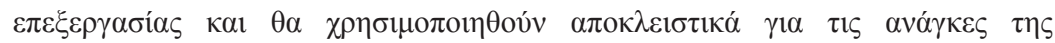

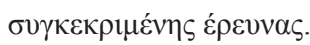

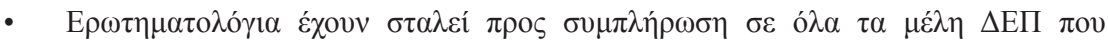

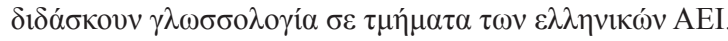

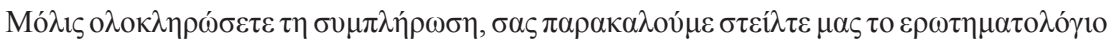

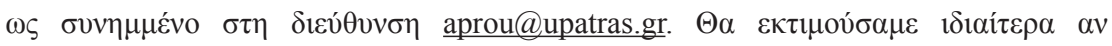

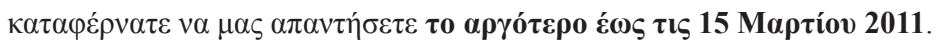

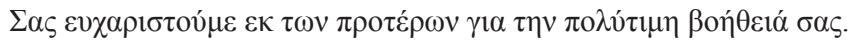

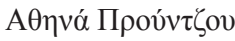

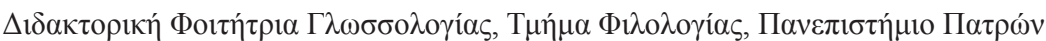

\begin{tabular}{|c|c|}
\hline \multicolumn{2}{|c|}{ 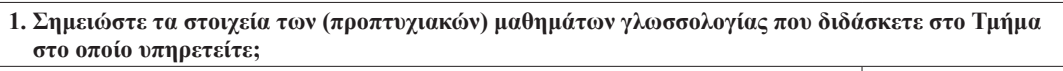 } \\
\hline 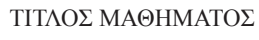 & ETO $\Sigma \Sigma \Pi O Y \Delta \Omega N$ \\
\hline$\alpha$. & \\
\hline$\beta$. & \\
\hline$\gamma$ & \\
\hline$\delta$. & \\
\hline$\varepsilon$ & \\
\hline
\end{tabular}

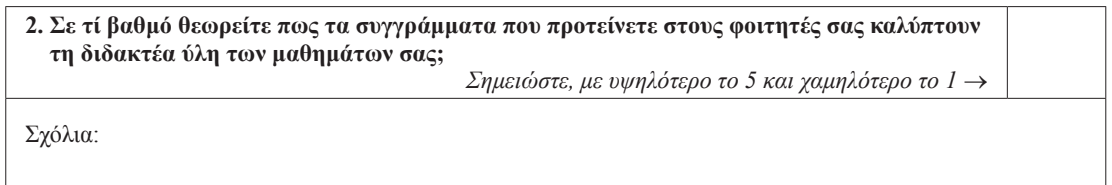




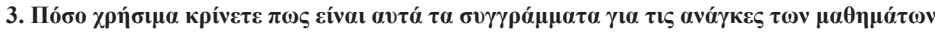

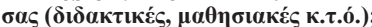

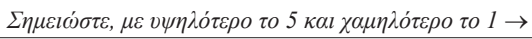

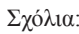

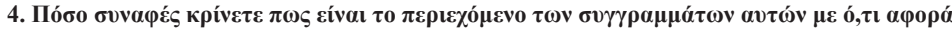

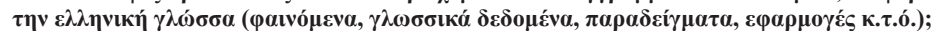

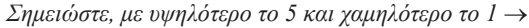

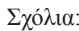

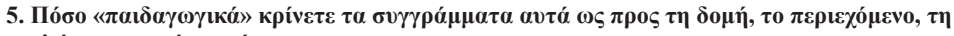

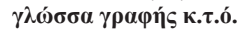

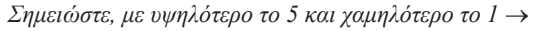

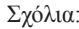

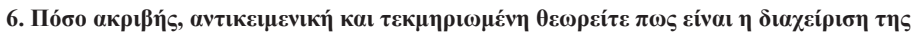

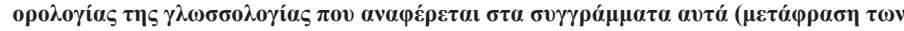

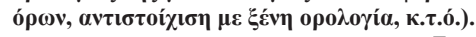

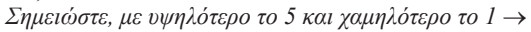

$\Sigma \chi 0 ́ \lambda 1 \alpha:$

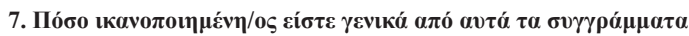

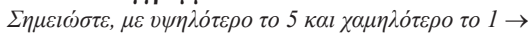

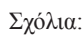




\section{Appendix II}

\begin{tabular}{|c|c|}
\hline Readability features & Measurable criteria for readability \\
\hline $\begin{array}{l}\text { Clearly and hierarchically } \\
\text { structured }\end{array}$ & $\begin{array}{l}\text { - Chapters and sections hierarchically structured and headed } \\
\text { - Chapter summary } \\
\text { - Index of terms } \\
\text { - References }\end{array}$ \\
\hline Appealing to the reader & $\begin{array}{l}\text { - Chapters and sections hierarchically structured and headed } \\
\text { - Illustrations } \\
\text { - Flagged terms in body text } \\
\text { - Chapter summary } \\
\text { - Practice exercises }\end{array}$ \\
\hline Graphically supported & - Pictures, tables, diagrams \\
\hline Attention drawn to key terms & $\begin{array}{l}\text { - Index of terms } \\
\text { - Mono/Bilingual glossary } \\
\text { - Flagged terms in body text }\end{array}$ \\
\hline Theory linked to practice & $\begin{array}{l}\text { - Application to Greek data } \\
\text { - Practice exercises/activities } \\
\text { - Pictures, tables, diagrams }\end{array}$ \\
\hline Sufficiently informative & $\begin{array}{l}\text { - Chapters and sections hierarchically structured and headed } \\
\text { - Mono/Bilingual glossary } \\
\text { - Application to Greek data } \\
\text { - Foot/Endnotes } \\
\text { - Author's CV } \\
\text { - Chapter summary } \\
\text { - Flagged terms in body text } \\
\text { - Generality of book title } \\
\text { - Back cover details }\end{array}$ \\
\hline
\end{tabular}




\section{Appendix III}

\begin{tabular}{|c|c|}
\hline Usability features & Measurable criteria for usability \\
\hline $\begin{array}{l}\text { Supporting practical work / } \\
\text { class work / homework }\end{array}$ & $\begin{array}{l}\text { - Practice exercises /activities } \\
\text { - Application to Greek data } \\
\text { - Index of terms } \\
\text { - Mono/Bilingual glossary } \\
\text { - Chapter summary }\end{array}$ \\
\hline Supplementing teaching & $\begin{array}{l}\text { - Practice exercises /activities } \\
\text { - References } \\
\text { - Pictures, tables, diagrams } \\
\text { - Mono/Bilingual glossary } \\
\text { - Chapter summary } \\
\text { - Chapters and sections hierarchically structured and headed }\end{array}$ \\
\hline $\begin{array}{l}\text { Introducing students to } \\
\text { topics }\end{array}$ & $\begin{array}{l}\text { - Chapters and sections hierarchically structured and headed } \\
\text { - Chapter summary } \\
\text { - Mono/Bilingual glossary } \\
\text { - Pictures, tables, diagrams } \\
\text { - Application to Greek data }\end{array}$ \\
\hline Illustrating concepts & $\begin{array}{l}\text { - Pictures, tables, diagrams } \\
\text { - Application to Greek data } \\
\text { - Mono/Bilingual glossary } \\
\text { - Practice exercises /activities }\end{array}$ \\
\hline $\begin{array}{l}\text { Serving as a revision and/or } \\
\text { reference guide }\end{array}$ & $\begin{array}{l}\text { - Chapters and sections hierarchically structured and headed } \\
\text { - Index of terms } \\
\text { - Flagged terms in body text } \\
\text { - Mono/Bilingual glossary } \\
\text { - Practice exercises /activities } \\
\text { - Chapter summary }\end{array}$ \\
\hline Serving as self-study manual & $\begin{array}{l}\text { - Chapters and sections hierarchically structured and headed } \\
\text { - Index of terms } \\
\text { - Flagged terms in body text } \\
\text { - Mono/Bilingual glossary } \\
\text { - Practice exercises /activities } \\
\text { - Chapter summary }\end{array}$ \\
\hline $\begin{array}{l}\text { Contributing to the } \\
\text { organisation and operation } \\
\text { of teaching }\end{array}$ & $\begin{array}{l}\text { - Chapters and sections hierarchically structured and headed } \\
\text { - Practice exercises / activities } \\
\text { - Pictures, tables, diagrams }\end{array}$ \\
\hline
\end{tabular}


Major Trends in Theoretical and Applied Linguistics 